University of Montana

ScholarWorks at University of Montana

Integrative Physiology and Athletic Training

Faculty Publications

Integrative Physiology and Athletic Training

$5-2012$

\title{
Substrate Use and Biochemical Response to a 3,211-km Bicycle Tour in Trained Cyclists
}

\author{
Dustin R. Slivka \\ University of Nebraska at Omaha \\ Charles Dumke \\ University of Montana - Missoula, charles.dumke@umontana.edu \\ Walter S. Hailes \\ University of Montana - Missoula \\ John S. Cuddy \\ University of Montana - Missoula \\ Brent Ruby \\ University of Montana - Missoula, brent.ruby@umontana.edu
}

Follow this and additional works at: https://scholarworks.umt.edu/hhp_pubs

Part of the Medicine and Health Sciences Commons

Let us know how access to this document benefits you.

\section{Recommended Citation}

Slivka, Dustin R.; Dumke, Charles; Hailes, Walter S.; Cuddy, John S.; and Ruby, Brent, "Substrate Use and Biochemical Response to a 3,211-km Bicycle Tour in Trained Cyclists" (2012). Integrative Physiology and Athletic Training Faculty Publications. 14.

https://scholarworks.umt.edu/hhp_pubs/14

This Article is brought to you for free and open access by the Integrative Physiology and Athletic Training at ScholarWorks at University of Montana. It has been accepted for inclusion in Integrative Physiology and Athletic Training Faculty Publications by an authorized administrator of ScholarWorks at University of Montana. For more information, please contact scholarworks@mso.umt.edu. 


\title{
Substrate use and biochemical response to a 3,211-km bicycle tour in trained cyclists
}

\author{
Dustin R. Slivka $\cdot$ Charles L. Dumke • \\ Walter S. Hailes $\cdot$ John S. Cuddy $\cdot$ Brent C. Ruby
}

Received: 11 February 2011/Accepted: 12 August 2011/Published online: 25 August 2011

(C) Springer-Verlag 2011

\begin{abstract}
The purpose of this study was to assess the physiological adaptations in physically fit individuals to a period of intensified training. Ten trained males cycled outdoors $\sim 170 \mathrm{~km} \mathrm{day}^{-1}$ on 19 out of 21 days. Expired gas was collected on days 1 and 21 during maximal graded exercise and used for the determination of gross efficiency and whole body substrate use. Muscle biopsies were obtained before and after exercise on days 2 and 22 for the determination of mtDNA/gDNA ratio, gene expression, metabolic enzyme activity and glycogen use. Muscle glycogen before and after exercise, fat oxidation, and gross efficiency increased, carbohydrate oxidation decreased $(p<0.05)$, and $V \mathrm{O}_{2 \max }$ did not change over the 21 days of training. Citrate synthase (CS), $\beta$-hydroxyacyl CoA dehydrogenase $(\beta$-HAD) and cytochrome c oxidase (COX) enzyme activity did not change with training. CS and $\beta$-HAD mRNA did not change with acute exercise or training. COX (subunit IV) mRNA increased with acute exercise $(p<0.05)$ but did not change over the 21 days. PGC- $1 \alpha$ mRNA increased with acute exercise, but did not increase to the same degree on day 22 as it did on day 2 $(p<0.05)$. UCP3 mRNA decreased with training
\end{abstract}

Communicated by Susan A. Ward.

D. R. Slivka $(\bowtie)$

School of Health Physical Education and Recreation,

University of Nebraska at Omaha, 6001 Dodge Street,

Omaha, NE 68182, USA

e-mail: dslivka@unomaha.edu

C. L. Dumke · W. S. Hailes - J. S. Cuddy - B. C. Ruby

Department of Health and Human Performance,

Montana Center for Work Physiology and Exercise Metabolism,

University of Montana, Missoula, MT, USA $(p<0.05)$. Acute exercise caused an increase in mitofu$\sin 2$ (MFN2) mRNA $(p<0.05)$ and a trend for an increase in mtDNA/gDNA ratio $(p=0.057)$. However, training did not affect MFN2 mRNA or mtDNA/gDNA ratio. In response to 3,211 km of cycling, changes in substrate use and gross efficiency appear to be more profound than mitochondrial adaptations in trained individuals.

Keywords MtDNA · Cycling · Efficiency · Training adaptation · Gene expression - Metabolic enzymes

\section{Introduction}

Endurance exercise training results in greater fatty acid oxidation and less carbohydrate oxidation for a given absolute workload (Hermansen et al. 1967; Hurley et al. 1984, 1986). Many of these adaptations can occur within the first 5-12 days of endurance training (Cadefau et al. 1994; Chesley et al. 1996; Phillips et al. 1996). Traditionally, the ability of trained individuals to oxidize greater amounts of fat is accounted for by increases in maximal activity of mitochondrial enzymes (Holloszy 1967). However, many of the changes in substrate use and metabolites have been observed without increased mitochondrial function as measured by maximal activity of mitochondrial enzymes (Phillips et al. 1996). Previous studies have demonstrated a parallel increase in oxidative enzymes and whole body substrate oxidation (Holloszy 1975), but lack a causal link.

The exact measure of mitochondrial function that best illustrates the oxidative potential of tissues remains elusive. Maximal oxidative enzyme capacities (Chesley et al. 1996; Phillips et al. 1996), balance of fission and fusion (Bach et al. 2003), cardiolipin content (Claypool 2009), and 
mitochondrial DNA (mtDNA) to genomic DNA ratios (Menshikova et al. 2005) have all been used to illustrate oxidative potential of muscle. Further complicating the time course of metabolic versus mitochondrial adaptation is the recent advances in mitochondrial morphology, where mitochondrion function is dictated by its state of fission and/or fusion as opposed to number or density (Bach et al. 2003). The lack of a "gold standard" measurement of mitochondrial function and the multiple aspects of mitochondrial function leaves this area of research complex and the interpretation of previous research difficult. The use of a multi-factorial approach to mitochondrial measurement (including enzyme function, relative mtDNA copy number and gene expression) may allow for a more complete, methodology-independent, understanding of mitochondrial adaptation. Specifically, we analyzed gene expression and enzymatic activities of the beta-oxidation marker $\beta$-hydroxyacyl CoA dehydrogenase $(\beta$-HAD), the Krebs cycle marker citrate synthase (CS), the electron transport chain marker cytochrome $\mathrm{C}$ oxidase, subunit IV (COX). Mitofusin2 (MFN2) was analyzed to address mitochondrial fission (Bach et al. 2003). Peroxisome-proliferator-activated receptor-gamma co-activator 1 alpha (PGC- $1 \alpha$ ) and uncoupling protein 3 (UCP3) were used as a marker for mitochondrial development and substrate use (Bezaire et al. 2007; Himms-Hagen and Harper 2001; Lin et al. 2004; Pilegaard et al. 2003; Wang et al. 2003; Wende et al. 2007). In order to address mitochondrial number the ratio of mitochondrial to genomic DNA (Menshikova et al. 2007) was analyzed. Additionally, Whole body fat and carbohydrate oxidation and local glycogen use were included based on the relationship between mitochondrial development and substrate use (Holloszy 1975). This approach is not all inclusive; nonetheless, it offers a unique approach to address the multiple mechanisms associated with mitochondrial function.

The purpose of this study was to implement a period of intensified training in physically fit individuals to access the physiological adaptations with special attention to mitochondrial and substrate use alterations. Since the mitochondria plays an important role in determining substrate use, we hypothesized that substrate use would change in parallel to mitochondrial function when using a multifactorial approach to mitochondrial measurement. Due to the training status of the individuals and the training stimulus that would be required to overload and induce mitochondrial changes in these trained individuals, a laboratory model was not feasible. Participant adherence to a lab-based protocol with the high training volume used in this investigation would have been low. Therefore, in order to provide an environment in which participants could withstand the training load and to increase application/ external validity, this investigation was completed in the field and was organized as a training camp/cycling tour in the western USA.

\section{Materials and methods}

\section{Subjects}

Ten $(n=10)$ male participants $(24 \pm 2$ years of age, $181 \pm 5 \mathrm{~cm}$ height) were recruited from the local triathlon and cycling community. These individuals were recruited due to their success in local endurance racing events and thus having a realistic chance of completing the protocols involved with the current investigation. Laboratory measures such as $V \mathrm{O}_{2 \max }$ were not used as part of the inclusion criteria as these measures may not be the best to access capacity to withstand the high exercise volume involved with the completion of the current protocol. The participants engaged in aerobic training for an average of $9.0 \pm 5.0 \mathrm{~h} \mathrm{week}^{-1}$ for the prior 4 weeks; however, no specific criteria were set for training volume or years practiced. Before any testing, participants read and signed an informed consent form approved by the institutional review board for the ethical use of human subject research.

Training, living conditions, nutrition, and stresses

All laboratory testing was completed in the same location before and after training. See timeline in Fig. 1. Day 2 and day 22 of cycling were completed on the same outdoor terrain $(169 \mathrm{~km})$ and at the same time of the day (starting at 8:00 am) and without exercise within $(20 \mathrm{~h})$. Average ride temperature during day 2 was slightly warmer (26 vs. $19^{\circ} \mathrm{C}$ ), less humid ( 31 vs. $43 \% \mathrm{RH}$ ), but with similar wind speeds $\left(<2.24 \mathrm{~m} \mathrm{~s}^{-1}\right)$ than day 22 . The period of intensified training was organized as a bicycle tour through the mountains of western USA. Participants cycled at a selfselected power output for the bulk of the training time (except for scheduled performance trials and testing). Training consisted of cycling approximately $170 \mathrm{~km} \mathrm{day}^{-1}$ on 19 of the 22 days. Days 1 and 21 were scheduled as max test days (only maximal exercise capacity test, no road cycling) and day 12 was a rest day. On the days of the max tests the participants did not exercise for $>16 \mathrm{~h}$ prior. Participants completed the training on identical (size adjusted) road racing bicycles (Orbea USA, North Little Rock, AR) equipped with a power tap power meter integrated into the rear wheel (Powertap Pro 2.4 wireless, Saris Cycling, Madison, WI). Ad libitum energy was provided in the form of a hot breakfast and dinner that was well balanced and high in carbohydrate from a catering service that specialized in bicycling tours. Dietary intake was not recorded. However, participants were encouraged to 
Fig. 1 Schematic overview of experimental testing associated with 22 days of intensified training

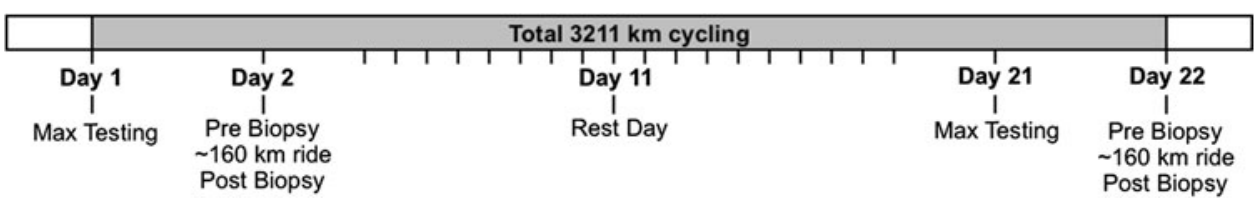

consume adequate calories and to stay hydrated. Due to the fact that participants maintained body weight and body composition, it can be assumed that energy balance and hydration were maintained (Table 1). During the time spent cycling, participants were provided with ad libitum commercially available supplemental foods [energy bars and sport drink (Gatorade, Chicago, IL)]. On day 2 and 22 (biopsy days), participants consumed the same amount and form of energy with no consumption of calories in the last hour of cycling before the muscle biopsy in order to control for dietary influence of substrate use.

\section{Body composition}

Prior to any other physiological testing body density was determined using hydrodensitometry and corrected for estimated residual lung volume on days 1 and 21. Net underwater weights were recorded using load cells (Exertech, Dresbach, MN). Body density was then converted to body composition using the Siri equation (Siri 1993).

\section{Maximal exercise capacity}

Maximum oxygen consumption $\left(V \mathrm{O}_{2 \max }\right)$ and power associated with $V \mathrm{O}_{2 \max }$ was measured for each subject (Rest days 1 and 21) using a graded exercise protocol (starting at $95 \mathrm{~W}$ and increasing $35 \mathrm{~W}$ every $3 \mathrm{~min}$ ) on an electronically braked cycle ergometer trainer (Computrainer, RacerMate Inc., Seattle, WA). Following an overnight fast, participants rode to volitional fatigue (self-determined by the subject as the point at which they could not continue) at a self-selected cadence. Maximum power was calculated as the highest completed stage (in W) + the proportion of time in the last stage multiplied by the $35 \mathrm{~W}$ stage increment. Expired gases were collected and averaged in $15 \mathrm{~s}$ intervals during the test using a calibrated metabolic cart (Parvomedics, Inc., Salt Lake City, UT).

Table 1 Maximal aerobic capacity and body composition

\begin{tabular}{lllll}
\hline & $\begin{array}{l}V \mathrm{O}_{2 \max } \\
\left(\mathrm{L} \mathrm{min}^{-1}\right)\end{array}$ & Max watts & $\begin{array}{l}\text { Weight } \\
(\mathrm{kg})\end{array}$ & $\begin{array}{l}\text { Body fat } \\
(\%)\end{array}$ \\
\hline Day 1 & $4.49 \pm 0.35$ & $355 \pm 38$ & $72.2 \pm 7.9$ & $11.1 \pm 3.3$ \\
Day 21 & $4.57 \pm 0.58$ & $365 \pm 44$ & $71.5 \pm 7.1$ & $9.9 \pm 2.3$ \\
$t$ test & $p=0.529$ & $p=0.275$ & $p=0.139$ & $p=0.071$ \\
\hline
\end{tabular}

Data are mean $\pm \mathrm{SD}$

\section{Substrate use}

Following an overnight fast $(>10 \mathrm{~h})$, expired steady-state gas samples from the $V \mathrm{O}_{2 \max }$ tests (last minute of each stage when RER <1.0) on day 1 and day 21 (rest days) were used to calculate whole-body carbohydrate and fat oxidation using the equation of Péronnet and Massicotte (Jeukendrup and Wallis 2005). Prior to this test, on both days 1 and 21 , subjects had not exercised for $>16 \mathrm{~h}$.

\section{Gross efficiency}

Gross efficiency was calculated for each workload during the $V \mathrm{O}_{2 \max }$ tests until the respiratory exchange ratio exceeded 1.00. The calculation was done in accordance with the methodology demonstrated to be reliable by (Moseley and Jeukendrup 2001).

\section{Biopsies}

Biopsies were obtained pre and post exercise on days 2 and 22 for the analysis of muscle glycogen, metabolic enzymes activity, metabolic gene expression, and genomic and mitochondrial DNA copy number (see below). The pre exercise biopsy was obtained approximately $10 \mathrm{~min}$ before exercise and the post muscle biopsy was completed within 20 min after exercise. Biopsies were taken from the vastus lateralis muscle using a 4-5 mm Bergstrom percutaneous muscle biopsy needle with the aid of suction. Pre and post biopsies were obtained from the same leg using a separate incision $2 \mathrm{~cm}$ proximal to the previous biopsy. After excess blood, connective tissue, and fat were removed, tissue samples were immersed in liquid nitrogen and stored at $-80^{\circ} \mathrm{C}$ for later analysis.

\section{Glycogen}

Muscle glycogen was analyzed using an enzymatic spectrophotometric method. Samples were weighed upon removal from a $-80^{\circ} \mathrm{C}$ freezer and placed in $0.5 \mathrm{ml}, 2 \mathrm{~N} \mathrm{HCl}$ solution. The sample solutions were weighed, incubated for $2 \mathrm{~h}$ at $100^{\circ} \mathrm{C}$ in an oven, then re-weighed and re-constituted to their original weight using distilled water. To normalize $\mathrm{pH}, 1.5 \mathrm{ml}$ of $0.67 \mathrm{NaOH}$ was added. A volume of this muscle extract $(100 \mu \mathrm{l})$ was added to $1 \mathrm{ml}$ of Infinity glucose (HK) liquid stable reagent (Thermo Fisher Scientific, Waltham, MA), and read on a spectrophotometer at $340 \mathrm{~nm}$. Muscle glycogen was 
Table 2 Primers and probes used for real-time PCR

\begin{tabular}{llll}
\hline Gene & Primer 1 & Primer 2 & Probe \\
\hline B-globin & TGAAGGCTCATGGCAAGAAA & AAAGGTGCCCTTGAGGTTGTC & CCAGGCCATCACTAAAGGCACCGA \\
$\beta$-HAD & TGGCTTCCCGCCTTGTC & TTGAGCCGGTCCACTATCTTC & CGCCATACAGACCACAAAGCGGAA \\
COX & CTCTCCCCAGATGATGCCTTT & GGTCTCTTTGGGCGGAAGAC & CCCTGGATACTCTTACACAGCCGCCAA \\
CS & GACTACATCTGGAACACACTCCAACTCA & CGCGGATCAGTCTTCCTTAGTAC & ACGGGTTGTCCAGGCTATGGCCA \\
GAPDH & GCTCTCTGCTCCTCCTGTTC & ACGACCAAACCGTTGACTC & ACATCAGCCGCATCTTCTT \\
MFN2 & CCAGAGGGCAGAACTTTCTC & ATGCATCCCACTTAAGCAC & AGAGGCATCAGTGAGGTGCT \\
MtDNA & GCGGATGATTCAGCCATAATTTA & GACGCCTCAACCGCCTTT & CATCAATCGCCCACATCACTCGAGAC \\
PGC-1 $\alpha$ & TGAGAGGGCCAAGCAAAG & ATAAATCACACGGCGCTCTT & AGAGGCAGAGGCAGAAGG \\
UCP3 & TGACTCCGTCAAGCAGGTGTAC & CAAAATCCGGGTAGTGAGGCT & CCCCCAAAGGCGCGGACAAC \\
\hline
\end{tabular}

$B$-Globin beta globin, $\beta$-HAD beta-hydroxyacyl CoA dehydrogenase, $C O X$ cytochrome c oxidase subunit IV, $C S$ citrate synthase, GAPDH Glyceraldehyde 3-phosphate dehydrogenase, MFN2 mitofusin 2, MtDNA mitochondrial DNA, $P G C$-1 $\alpha$ peroxisome-proliferator-activated receptor-gamma co-activator 1 alpha, UCP3 uncoupling protein 3

then calculated using the extinction co-efficient of NADH. Muscle glycogen concentrations are expressed in mmol kg ${ }^{-1}$ wet weight of muscle tissue.

\section{Metabolic enzymes}

Muscle ( $\sim 10 \mathrm{mg})$ from pre exercise biopsies on day 2 and 22 were mechanically homogenized in CelLytic MT mammalian tissue lysis/extraction reagent (Sigma \#C3228, Sigma Aldrich, St.Louis MO). For $\beta$-hydroxyacyl CoA dehydrogenase ( $\beta$-HAD), $20 \mu$ l of homogenate was added to $970 \mu \mathrm{l}$ of a reaction solution $(6 \mathrm{ml} 1 \mathrm{mM}$ EDTA, $4 \mathrm{ml}$ $1 \mathrm{M}$ Imidazole (Sigma \#68268), $3.5 \mathrm{ml} 1 \mathrm{mM}$ NADH (Sigma \#N4505-100 mg), and $86.5 \mathrm{ml}$ distilled water) and $10 \mu \mathrm{l}$ of $5 \mathrm{mM}$ Acetylacetyl Co-A (Sigma \#A1625). The elimination of NADH was then followed for $90 \mathrm{~s}$ at $340 \mathrm{~nm}$. Enzyme activity was calculated with the extinction co-efficient for NADH (6.22). Citrate synthase (CS) was assayed using a citrate synthase assay kit (Sigma \#CS0720) according to the manufacturer's specifications. Cytochrome $\mathrm{c}$ oxidase (COX) was assayed using the cytochrome c oxidase Assay Kit (CYTOCOX1, Sigma, Saint Louis, Missouri) according to the manufacturer's protocol. All enzyme activities were measured at $25^{\circ} \mathrm{C}$.

Skeletal muscle mRNA isolation

An 8-20 mg piece of skeletal muscle was homogenized in $800 \mu \mathrm{l}$ of trizol (Invitrogen, Carlsbad CA, Cat\# 15596-018) using an electric homogenizer (Tissue Tearor, Biosped Products Inc, Bartlesville OK). Samples were then incubated at room temperature for $5 \mathrm{~min}$ after which $200 \mu \mathrm{l}$ of chloroform per 1,000 $\mu \mathrm{l}$ of trizol was added and shaken vigorously by hand. After an additional incubation at room temperature for 2-3 min the samples were centrifuged at 12,000 $\mathrm{g}$ for $15 \mathrm{~min}$ and the aqueous phase was transferred to a fresh tube. mRNA was precipitated by adding $400 \mu \mathrm{l}$ of isopropyl alcohol and incubated overnight at $-20^{\circ} \mathrm{C}$. The next morning samples were centrifuged at $12,000 \mathrm{~g}$ for $10 \mathrm{~min}$ at $4^{\circ} \mathrm{C}$ and the mRNA was washed by removing the supernatant and adding $800 \mu \mathrm{l}$ of $75 \%$ ethanol. Samples were vortexed and centrifuged at $7,500 \mathrm{~g}$ for $5 \mathrm{~min}$ at $4^{\circ} \mathrm{C}$. mRNA was re-dissolved in $100 \mu \mathrm{l}$ RNase-free water after the supernatant was removed and the mRNA pellet was dried. The RNA was cleaned using the RNeasy mini kit (Qiagen, Valencia CA, Cat\#74104) according to the manufacturer's protocol using the additional DNase digestion step (RNase-free DNase set, Qiagen, Valencia CA, Cat\# 79254). RNA purity was analyzed by the A260:A280 ratio and amount quantified on a nano-spectrophotometer (nano-drop ND1000, Wilmington DE).

cDNA synthesis

First-strand cDNA synthesis was achieved using Superscript-first-strand synthesis system for RT-PCR kit (Invitrogen, Carlsbad CA, Cat \#11904-0818) according to the manufacturer's protocol. Each sample (days 2 and 22 pre and post) within a given subject contained the same amount of RNA ( $459 \pm 27 \mathrm{ng}$ ). The resulting cDNA was then diluted $2 \times$ using RNase-free water in order to have adequate volume for RT-PCR and frozen for later analysis.

\section{Real-time RT-PCR}

Primer and probe sequences are presented in Table 2. Each $25 \mu \mathrm{l}$ reaction volume contained $500 \mathrm{nM}$ primers, $250 \mathrm{nM}$ probe (PimeTime qPCR assay, Integrated DNA technologies), $1 \times$ FastStart TaqMan Probe master (Roche Applied Science, Indianapolis IN), and $2.5 \mu \mathrm{l}$ of sample 
cDNA. PCR was then run using the Bio-Rad I Cycler iQ5 Real-Time PCR Detection system (Bio-Rad, Hercules CA) using a 2-step Roche protocol (1 cycle at $50^{\circ} \mathrm{C}$ for $10 \mathrm{~min}, 1$ cycle at $95^{\circ} \mathrm{C}$ for $10 \mathrm{~min}$, followed by 40 cycles of $95^{\circ} \mathrm{C}$ for $15 \mathrm{~s}$ followed by $60^{\circ} \mathrm{C}$ for $1 \mathrm{~min}$ ). Quantification of mRNA was calculated using the $2^{-\Delta \mathrm{CT}}$ method as described by Livak and Schmittgen (2001) and used in a similar context as the current investigation (Dumke et al. 2009). Briefly, the $2^{-\Delta C T}$ method is the difference or relative abundance of a gene of interest versus the internal control or housekeeping gene and then transformed $\left(2^{-x}\right)$ since CT data are logarithmic. This method allows for the comparison of pre exercise values on day 2 versus day 22 (in arbitrary units), whereas the $2^{-\Delta \Delta \mathrm{CT}}$ method does not. The $2^{-\Delta \Delta \mathrm{CT}}$ method would yield relative fold change values of " 1 " for both day 2 pre and day 22 pre. GAPDH was used as the reference housekeeping gene as it has been demonstrated to be the most stable among other common housekeeping genes with exercise (Jemiolo and Trappe 2004). In the current study the stability of GAPDH was analyzed applying the above-described $2^{-\Delta \mathrm{CT}}$ method to pre exercise versus post-exercise GAPDH. There was no difference in GAPDH with exercise $(p=0.498)$.

\section{Mitochondrial DNA}

DNA was extracted from skeletal muscle samples using a QIamp DNA mini kit (Qiagen, Valencia CA, Cat\#51304). Relative copy number of mtDNA (nucleotides 14,918-14,986) per diploid nuclear DNA ( $\beta$-Globin) was determined based on the markers previously published (Miller et al. 2003). The $\beta$-Globin gene was used as the stable reference nuclear gene since it is a known single copy gene that can act as a marker of diploid genome content (Lawn et al. 1980). Sequences of probes and primers are presented in Table 1. All samples were run in duplicate. PCR for mtDNA and $\beta$-Globin were detected using the procedures described above. The threshold cycle number $\left(\mathrm{C}_{\mathrm{T}}\right)$ for mtDNA and $\beta$-Globin were used for the calculation of relative copy number as previously described (Szuhai et al. 2001).

\section{Statistics}

Differences in training parameters over the training period were analyzed using paired $t$ tests. Glycogen, mRNA, and DNA ratio were compared over the training period and pre to post exercise using two-way repeated-measures ANOVAs. Substrate utilization and gross efficiency were compared across graded exercise intensities and pre to post training using repeated-measures ANOVAs. In the event of an ANOVA significant $F$ ratio the Fisher's Protected LSD procedure was used to detect where differences occurred. All ANOVAs were performed using SPSS for windows Version 9 (Chicago, IL). A probability of type I error less than $5 \%$ was considered significant $(p<0.05)$. All data are reported as mean $\pm \mathrm{SD}$.

\section{Results}

Training

During the intensified training period the participants cycled $3,211 \mathrm{~km}\left(169 \pm 13 \mathrm{~km}\right.$ day $^{-1}+1$ rest day +2 max test days) over varied terrain. The riders averaged $167 \pm 13 \mathrm{~W}$ for $281 \mathrm{~min}$ each training day. While the average intensity remained low $(47.2 \pm 3.4 \%$ of pretraining maximum power), the daily mean time spent at an intensity greater than $70 \%$ of maximum power output was on average $71 \mathrm{~min}$, of which $21 \mathrm{~min}$ were spent above $90 \%$, during each day of riding. Average power output and cycling time on day 2 and day 22 that were conducted on the same terrain and distances were similar (187 \pm 16 vs. $188 \pm 22 \mathrm{~W}$ and $5.40 \pm 0.44$ vs. $5.55 \pm 0.09 \mathrm{~h}$, respectively), thus allowing reasonable comparison between the two muscle biopsy days.

\section{Maximal exercise capacity}

Markers of fitness and performance including $V \mathrm{O}_{2 \max }$ and max power output during the $V \mathrm{O}_{2 \max }$ test on days 1 and 21 did not change over the intensified training period (Table 1). Additionally, body weight, and percent body fat did not change (Table 1).

Substrate use

Regardless of day muscle glycogen decreased with exercise (Day 2, $166 \pm 44 \mathrm{~mm} \mathrm{~kg}^{-1}$ wet wt pre to $46 \pm 6 \mathrm{~mm}$ $\mathrm{kg}^{-1}$ wet wt post; Day 22, $197 \pm 32 \mathrm{~mm} \mathrm{~kg}^{-1}$ wet wt pre to $102 \pm 38 \mathrm{~mm} \mathrm{~kg}^{-1}$ wet wt post $(p=0.002$, main effect of exercise) and was higher $(p<0.001$, main effect of training) on day 22 versus day 2 . There was a trend ( $p=0.09$ ) for lower glycogen use on day 22 versus day 2 , which left $122 \%$ of day 2 glycogen available at the end of exercise on day 22. Whole body fat oxidation was elevated $(p<0.05)$ at $165,200,235$, and $270 \mathrm{~W}$ (Fig. 2a) during the incremental exercise on day 21 compared with day 1 . Whole body carbohydrate oxidation decreased with training $(p<0.05)$ at all sub-maximal exercise intensities (Fig. 2b). Gross efficiency was higher $(p<0.05)$ at all sub-maximal exercise intensities after training (Fig. 3). 

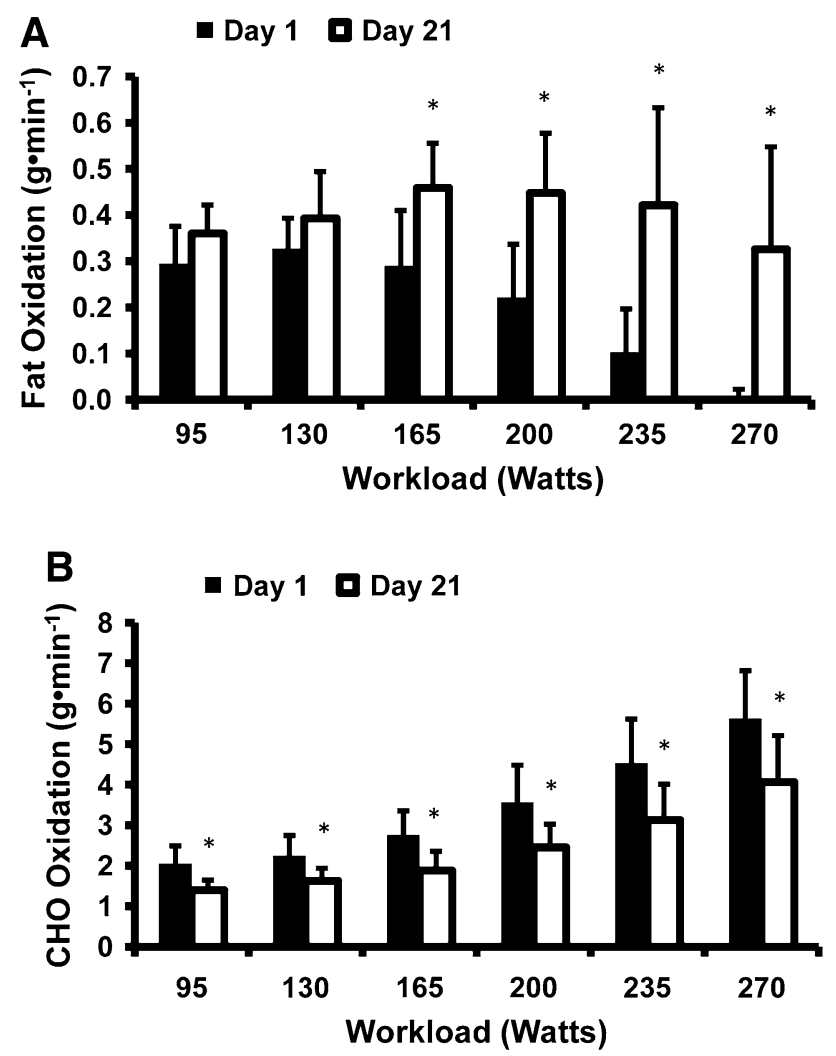

Fig. 2 Fat oxidation (a) and carbohydrate oxidation (b) during the maximal aerobic capacity test on day 1 and day 21 of the intensified training protocol. ${ }^{*} p<0.05$ from day 1 of the same intensity. Data are mean $\pm \mathrm{SD}$

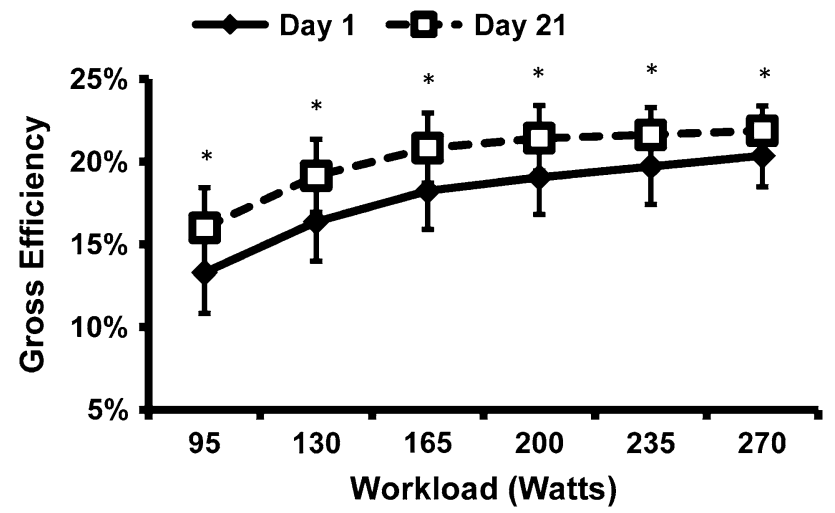

Fig. 3 Gross efficiency during the maximal aerobic capacity test on day 1 and day 21 of the intensified training protocol. $* p<0.05$ from day 1 of the same intensity. Data are mean $\pm \mathrm{SD}$

\section{Metabolic enzymes}

Mitochondrial maximal enzyme activities, from pre exercise samples, associated with beta-oxidation ( $\beta$-HAD), Krebs cycle (CS), and the electron transport chain (COX) did not significantly change with training (Table 3 ).
mRNA

Our housekeeping gene (GAPDH) did not change with exercise or training ( $p>0.05$, see "Materials and methods" for GAPDH stability information). PGC- $1 \alpha$ expression increased with acute exercise, but did not increase to the same degree on day 22 as it did on day 2 (exercise $\times$ training interaction, Table 3 ). UCP3 did not increase with acute exercise, but did decrease with 21 days of training (Table 3). MFN2 increased with acute exercise and responded the same on day 22 as it did on day 1 (Table 3). $\beta$-HAD mRNA and CS mRNA did not change with acute exercise or with training (Table 3). COX mRNA increased with acute exercise, but was unaffected with training (Table 3).

Mitochondrial DNA content

The relative copy number of mtDNA per diploid nuclear DNA did not increase with training, but did show a trend toward an increase with acute exercise $(p=0.057$, Table 3).

\section{Discussion}

This investigation reports metabolic outcomes of an intensified training program in already trained individuals. The main finding was that despite robust changes in substrate use and cycling efficiency, markers of mitochondrial development showed minimal adaptation in these trained individuals. The modest changes in mitochondrial adaptation were despite a very aggressive endurance training protocol that included cycling $3,211 \mathrm{~km}$ and two incremental maximal exercise tests over the course of 22 days. This training protocol was very similar in terms of days and riding time to the grand cycling tours. However, the participants in the current study were not capable of producing the same power as elite riders (Lucia et al. 2003). The current riders averaged $167 \mathrm{~W}$ throughout this training period while grand tour riders have been reported to average between 200 and $250 \mathrm{~W}$ on flat stages with an even greater power output on mountain stages (Lucia et al. 2003).

The training-induced metabolic response is traditionally explained by peripheral adaptations including increased size and number of mitochondria. However, previous evidence suggests many training adaptations occur very early, during which it is unlikely that mitochondrial protein would have time to adapt. After just 3 days of training muscle metabolites decrease, while glucose and lactate transporters (Green et al. 2008a), $\mathrm{Na}^{+}-\mathrm{K}^{+}$-ATPase pumps (Green et al. 2008b), and sarco-endoplasmic reticulum 
Table 3 Enzyme activity, mRNA (relative to GAPDH), and DNA pre and post exercise on day 2 and day 22 of intensified training

\begin{tabular}{|c|c|c|c|c|c|c|c|}
\hline & \multicolumn{2}{|l|}{ Day 2} & \multicolumn{2}{|l|}{ Day 22} & \multicolumn{3}{|l|}{ Statistics } \\
\hline & Pre & Post & Pre & Post & $\begin{array}{l}\text { Day } \\
\text { (main effect) }\end{array}$ & $\begin{array}{l}\text { Pre-post } \\
\text { (main effect) }\end{array}$ & $\begin{array}{l}\text { Day } 2 \text { post versus } \\
\text { Day } 22 \text { post } \\
\text { (interaction) }\end{array}$ \\
\hline \multicolumn{8}{|l|}{ Enzyme activity } \\
\hline$\beta$-HAD & $5.59 \pm 0.87$ & & $5.36 \pm 0.90$ & & $p=0.397$ & & \\
\hline $\mathrm{CS}$ & $31.69 \pm 4.78$ & & $34.84 \pm 3.33$ & & $p=0.055$ & & \\
\hline $\mathrm{COX}$ & $1.21 \pm 0.39$ & & $1.76 \pm 0.86$ & & $p=0.126$ & & \\
\hline \multicolumn{8}{|l|}{ mRNA } \\
\hline$\beta$-HAD & $11.30 \pm 4.33$ & $8.42 \pm 2.63$ & $10.27 \pm 3.82$ & $10.00 \pm 3.25$ & $p=0.690$ & $p=0.253$ & \\
\hline $\mathrm{CS}$ & $26.4 \pm 7.67$ & $25.83 \pm 3.9$ & $29.24 \pm 8.5$ & $31.82 \pm 7.47$ & $p=0.095$ & $p=0.630$ & \\
\hline $\mathrm{COX}$ & $139 \pm 47$ & $231 \pm 76^{*}$ & $157 \pm 29$ & $211 \pm 57^{*}$ & $p=0.971$ & $p=0.001$ & \\
\hline PGC- $1 \alpha$ & $2.86 \pm 1.16$ & $22.68 \pm 9.62$ & $2.87 \pm 0.74$ & $14.76 \pm 6.30^{*}$ & $p=0.006$ & $p<0.001$ & $p=0.003$ \\
\hline UCP3 & $4.84 \pm 1.91$ & $5.63 \pm 2.60$ & $3.06 \pm 1.18$ & $4.16 \pm 1.91^{\dagger}$ & $p=0.014$ & $p=0.131$ & \\
\hline MFN2 & $8.91 \pm 4.96$ & $12.56 \pm 8.26^{*}$ & $7.51 \pm 3.31$ & $10.04 \pm 4.19^{*}$ & $p=0.361$ & $p=0.002$ & \\
\hline \multicolumn{8}{|l|}{ DNA } \\
\hline mtDNA/gDNA & $1,028 \pm 334$ & $1,260 \pm 467$ & $921 \pm 370$ & $1,382 \pm 639$ & & & \\
\hline
\end{tabular}

Data are mean $2^{-\Delta C T} \pm \mathrm{SD}$

$\beta$-HAD Beta-hydroxyacyl CoA dehydrogenase, $C S$ citrate synthase, $C O X$ cytochrome c oxidase, $P G C$ - $1 \alpha$ peroxisome-proliferator-activated receptor-gamma co-activator 1 alpha, $U C P 3$ uncoupling protein 3, MFN2 Mitofusin 2, $m t D N A / g D N A$ relative copy number of mitochondrial DNA (mtDNA) per diploid genomic nuclear DNA (gDNA)

$* p<0.05$ from pre (main effect)

${ }^{\dagger} p<0.05$ from day 2 (main effect)

* $p<0.05$ from day 2 Post (interaction)

$\mathrm{Ca}^{++}$ATPase (SERCA) pumps (Duhamel et al. 2007) increase. Following 5-12 days of training, a reduced reliance on muscle glycogen is observed (Phillips et al. 1996). These adaptations occur without a parallel increase in oxidative phosphorylation as measured by maximal enzyme maximal activity. In the current study, substrate use was altered while mitochondrial enzyme maximal activities, $V \mathrm{O}_{2 \max }$, and maximum power output were not. These observations support the notion that metabolic shifts may happen independently of mitochondrial capacity alterations, as has been previously reported in untrained individuals (Phillips et al. 1996). From the current data it cannot be determined if the observed shifts in substrate use reflect a chronic training adaptation or the rise in fat oxidation that continues for days after an acute exercise bout (Henderson et al. 2007). However, substrate use was determined in the current study following an overnight fast, and more than $16 \mathrm{~h}$ after their last bout of exercise. This would likely lessen, but not completely account for the acute effects on substrate use. In addition, subjects were engaged in normal training prior to the pre substrate use determination although not to the same magnitude as the post. Both possibilities (acute or chronic effect of training on substrate use) provide evidence of the observed disconnect between mitochondrial adaptations and substrate use.
While a change in the maximal activities of these enzymes would imply a change in protein content, there is the possibility that these enzymes do not fully represent the complexity of mitochondrial morphology. To address this concern, we have included measures of additional mRNA and DNA. These measures address other possible changes within the mitochondria and ultimately the oxidative potential of the muscle. In general, the mRNA for the measured enzymes followed the same pattern as the maximal enzyme activities. However, COX mRNA showed no difference with training, but did increase with acute exercise further highlighting the complexity of the mechanisms involved and indicate elevated mitochondrial turnover after acute endurance exercise.

Mitochondrial uncoupling protein 3 (UCP3) is highly expressed in skeletal muscle, and despite a considerable amount of investigation the role of UCP3 is yet to be conclusively determined. UCP3 mRNA is typically increased with acute exercise (Schrauwen et al. 2002) and decreased with endurance training (Schrauwen et al. 2005). It has also been suggested that the acute response may be different between trained and untrained individuals (Schmutz et al. 2006) although the current data do not statistically support an altered UCP3 response with training. The current UCP3 mRNA data did not increase with acute exercise, but did demonstrate a reduction with training. The 
impact these changes have on the mitochondria and whole body substrate use is unclear. Over-expression of UCP3 in mouse skeletal muscle has been shown to increase fatty acid oxidation (Wang et al. 2003). Therefore, it is possible that UCP3 expression may promote an increase in fatty acid oxidation during acute exercise. However, this explanation does not provide a model for reduced UCP3 and increased fatty acid oxidation following training. Alternatively, the reduced levels of UCP3 after training may be a factor related to reactive oxygen species (ROS) mitigation or fatty acid anion export (Bezaire et al. 2007). From measures in this study, the oxidative capacity of muscle seems to be unchanged. Thus, it is unlikely that UCP3 is lowered due to an increased mitochondrial capacity to withstand fatty acid flux and less of a need for UCP3 mediated export of fatty acid anions from the mitochondria as put forth in the model by Himms-Hagen and Harper (2001). Clearly, more research is needed to understand the mechanism associated with UCP3 alterations with exercise and training.

The transcriptional co-activator protein PGC- $1 \alpha$ is induced in human skeletal muscle by exercise and mediates many of the adaptations to exercise (Pilegaard et al. 2003). Transgenically over-expressed PGC- $1 \alpha$ in mice induces mitochondrial biogenesis and yields muscle with an increased oxidative capacity (Wende et al. 2007). PGC- $1 \alpha$ is required for expression of many mitochondrial genes (Lin et al. 2004) and the loss of PGC- $1 \alpha$ leads to exercise intolerance and significant deficiencies in oxidative metabolism. Thus, $\mathrm{PGC} 1 \alpha$ is an important regulator of mitochondrial biogenesis and as such is an attractive marker of mitochondrial development potential. The current protocol yielded a large increase in PGC1 $\alpha$ mRNA with exercise on day 2. However, the increase on day 22 was smaller than that on day 2, despite the same amount of work performed on those 2 days (180 \pm 16 and $188 \pm 21$ average watts over the same course; $p>0.05$ ). Whether this is related to less reliance on muscle glycogen and subsequent AMPK activity (Wojtaszewski et al. 2003), or an attenuated hormonal response is beyond the scope of our data. Previous research evaluating PGC- $1 \alpha$ response with training has ranged from no difference in response to exercise before and after 9 days of training (Tunstall et al. 2002) to an increased PGC- $1 \alpha$ response after 4 weeks of training (Pilegaard et al. 2003). The exact reason for conflicting results between studies is not evident. However, these projects differed in subject fitness, training duration, training intensity, mode of exercise, and muscle sampling time making direct comparisons difficult. Specifically, the previous investigations (Pilegaard et al. 2003; Tunstall et al. 2002) were conducted using untrained participants, a much shorter exercise duration $(\sim 1 \mathrm{~h})$, and a higher average exercise intensity $\left(63-70 \%\right.$ of $\left.V \mathrm{O}_{2 \max }\right)$ than the current study. The exact impact that these factors have on the results is unknown. However, the current study provides good external validity to endurance athletes who do train with high volumes and low average intensity. It should be pointed out that while the current average intensity was low, the participants spent an average of $71 \mathrm{~min}$ each cycling day at intensities greater than $70 \%$. Therefore, intensity may not be the key factor in these differing results.

Recent interest in mitochondrial function has suggested that mitochondria undergo constant fusion and fission (Liu et al. 2009). The current data demonstrate that MFN2 mRNA increases acutely following a $\sim 5 \mathrm{~h}$ bout of cycling exercise, but not over 21 days of training. This is supportive of the role of MFN2 enhancing mitochondrial metabolism (Bach et al. 2003). The present study also shows a trend toward acute increases in mtDNA/gDNA ratios, but no change with training. Previous evidence in the literature has suggested that the mtDNA/gDNA ratio is an indicator of mitochondrial capacity (Menshikova et al. 2007). It is important to point out that these studies used subjects undergoing an exercise intervention with the goals of weight loss (Menshikova et al. 2007). Studies in previously trained humans were not able to demonstrate an increase in this mitochondrial marker (Yeo et al. 2008) while another study reports a decrease with acute fatiguing exercise (Marcuello et al. 2005). Conflicting results may be due to the variability in this marker. It is unclear whether this variability is methodological, a function of mixed fiber sampling, fiber recruitment, exercise duration and intensity, or perhaps as we propose here, a complex fusion/fission interaction as the result of exercise. Exercise has been shown to increase mitochondrial fusion (Cartoni et al. 2005), but it is unclear as to the fate of the relative mtDNA copy number during the fusion events. It has been suggested that fusion results in mtDNA recombination (Ono et al. 2001); however, direct evidence of this recombination does not yet exist. The rates of fusion and fission also affect mitochondrial function, with fusion resulting in greater oxidative capacity potential due to matrix content mixing but perhaps independent of enhanced expression of oxidative enzymes (Liu et al. 2009). This model is one possibility to explain the whole body oxidation changes we have seen here without apparent increases in oxidative enzyme activities.

Some concessions in study design were needed in order to accommodate the high volume training in a field environment. The current data should be interpreted in the context of the field approach taken in this study. While diet was controlled during pre and post substrate use measurements, diet was not controlled for throughout the 21 day training period. Participants were allowed daily ad libitum energy consumption from variable sources during the training period. Additionally, these participants entered the study in a trained state, which may have limited the potential for mitochondrial adaptation and makes comparison to research using 
untrained subjects difficult. Furthermore, biopsy timing may not have been ideal for the detection of gene expression as many of these genes could have a longer time course of activation or may reflect activation from subsequent days of exercise; however, the timing was identical on both days. Each day that biopsies were performed (for gene expression experiments) was preceded by a relatively light day which included only a graded exercise test (Fig. 1). To our knowledge there are no studies in the literature that have considered mRNA expression following a 5-6 h exercise protocol over 21 days of training. It should be noted that biopsies were obtained 5-6 $\mathrm{h}$ after the initiation of exercise on both day 2 and day 22. While the current approach to mitochondrial function measurement was multi-factorial, additional measures addressing mitochondrial fission and mitochondrial oxygen flux may add more clarity as to the mechanisms associated with training-induced mitochondrial adaptations in already trained individuals. Further work addressing these limitations is needed to elucidate the mechanism behind this cascade of events.

In summary, the current data suggest that the whole body oxidation changes observed with training cannot be solely explained by mitochondrial development and that a disconnect between whole body substrate use and mitochondrial development may exist. Mitochondrial development is a crucial adaptation to endurance training. However, other adaptations may contribute to metabolic changes when already trained individuals initiate a period of intensified training. Furthermore, mitochondrial adaptations during training may involve more complex fission/ fusion dynamics then classical methods can detect.

Ethical standards: The authors of this manuscript declare that all experiments comply with the current laws of the country in which they were performed.

Acknowledgments The views and conclusions contained herein are those of the authors and should not be interpreted as necessarily representing the official policies or endorsements, either expressed or implied, of Air Force Research laboratory or the U.S. government. Sponsored by Air Force Research Laboratory under agreement number FA5650-06-2-6740 and the University of Montana Grant program. We would like to acknowledge the assistance of the Molecular Biology Core Facility of The University of Montana supported in part by National Center for Research Resources Grants P20RR017670 and P20RR015583.

\section{References}

Bach D, Pich S, Soriano FX et al (2003) Mitofusin-2 determines mitochondrial network architecture and mitochondrial metabolism. A novel regulatory mechanism altered in obesity. J Biol Chem 278:17190-17197. doi:10.1074/jbc.M212754200

Bezaire V, Seifert EL, Harper ME (2007) Uncoupling protein-3: clues in an ongoing mitochondrial mystery. FASEB J 21:312-324. doi: 10.1096/fj.06-6966rev
Cadefau J, Green HJ, Cusso R, Ball-Burnett M, Jamieson G (1994) Coupling of muscle phosphorylation potential to glycolysis during work after short-term training. J Appl Physiol 76:2586-2593

Cartoni R, Leger B, Hock MB et al (2005) Mitofusins $1 / 2$ and ERRalpha expression are increased in human skeletal muscle after physical exercise. J Physiol 567:349-358. doi:10.1113/ jphysiol.2005.092031

Chesley A, Heigenhauser GJ, Spriet LL (1996) Regulation of muscle glycogen phosphorylase activity following short-term endurance training. Am J Physiol 270:E328-E335

Claypool SM (2009) Cardiolipin, a critical determinant of mitochondrial carrier protein assembly and function. Biochim Biophys Acta 1788:2059-2068. doi:10.1016/j.bbamem.2009.04.020

Duhamel TA, Stewart RD, Tupling AR, Ouyang J, Green HJ (2007) Muscle sarcoplasmic reticulum calcium regulation in humans during consecutive days of exercise and recovery. J Appl Physiol 103:1212-1220. doi:10.1152/japplphysiol.00437.2007

Dumke CL, Mark Davis J, Angela Murphy E et al (2009) Successive bouts of cycling stimulates genes associated with mitochondrial biogenesis. Eur J Appl Physiol 107:419-427. doi:10.1007/ s00421-009-1143-1

Green HJ, Bombardier E, Duhamel TA, Stewart RD, Tupling AR, Ouyang J (2008a) Metabolic, enzymatic, and transporter responses in human muscle during three consecutive days of exercise and recovery. Am J Physiol Regul Integr Comp Physiol 295:R1238-R1250. doi:10.1152/ajpregu.00171.2008

Green HJ, Duhamel TA, Stewart RD, Tupling AR, Ouyang J (2008b) Dissociation between changes in muscle $\mathrm{Na}^{+}-\mathrm{K}^{+}$-ATPase isoform abundance and activity with consecutive days of exercise and recovery. Am J Physiol Endocrinol Metab 294:E761-E767. doi:10.1152/ajpendo.00751.2007

Henderson GC, Fattor JA, Horning MA et al (2007) Lipolysis and fatty acid metabolism in men and women during the postexercise recovery period. J Physiol 584:963-981. doi:10.1113/jphysiol. 2007.137331

Hermansen L, Hultman E, Saltin B (1967) Muscle glycogen during prolonged severe exercise. Acta Physiol Scand 71:129-139

Himms-Hagen J, Harper ME (2001) Physiological role of UCP3 may be export of fatty acids from mitochondria when fatty acid oxidation predominates: an hypothesis. Exp Biol Med (Maywood) 226:78-84

Holloszy JO (1967) Biochemical adaptations in muscle. Effects of exercise on mitochondrial oxygen uptake and respiratory enzyme activity in skeletal muscle. J Biol Chem 242:2278-2282

Holloszy JO (1975) Adaptation of skeletal muscle to endurance exercise. Med Sci Sports 7:155-164

Hurley BF, Hagberg JM, Allen WK et al (1984) Effect of training on blood lactate levels during submaximal exercise. J Appl Physiol 56:1260-1264

Hurley BF, Nemeth PM, Martin WH 3rd, Hagberg JM, Dalsky GP, Holloszy JO (1986) Muscle triglyceride utilization during exercise: effect of training. J Appl Physiol 60:562-567

Jemiolo B, Trappe S (2004) Single muscle fiber gene expression in human skeletal muscle: validation of internal control with exercise. Biochem Biophys Res Commun 320:1043-1050. doi: 10.1016/j.bbrc.2004.05.223

Jeukendrup AE, Wallis GA (2005) Measurement of substrate oxidation during exercise by means of gas exchange measurements. Int J Sports Med 26(Suppl 1):S28-S37. doi:10.1055/s2004-830512

Lawn RM, Efstratiadis A, O'Connell C, Maniatis T (1980) The nucleotide sequence of the human beta-globin gene. Cell 21:647-651

Lin J, Wu PH, Tarr PT et al (2004) Defects in adaptive energy metabolism with CNS-linked hyperactivity in PGC-1alpha null mice. Cell 119:121-135. doi:10.1016/j.cell.2004.09.013 
Liu X, Weaver D, Shirihai O, Hajnoczky G (2009) Mitochondrial 'kiss-and-run': interplay between mitochondrial motility and fusion-fission dynamics. EMBO J 28:3074-3089. doi:10.1038/ emboj.2009.255

Livak KJ, Schmittgen TD (2001) Analysis of relative gene expression data using real-time quantitative PCR and the 2[-Delta Delta C(T)] Method. Methods 25:402-408. doi:10.1006/meth. 2001.1262

Lucia A, Earnest C, Arribas C (2003) The tour de France: a physiological review. Scand J Med Sci Sports 13:275-283

Marcuello A, Gonzalez-Alonso J, Calbet JA, Damsgaard R, LopezPerez MJ, Diez-Sanchez C (2005) Skeletal muscle mitochondrial DNA content in exercising humans. J Appl Physiol 99:13721377. doi:10.1152/japplphysiol.00289.2005

Menshikova EV, Ritov VB, Toledo FG, Ferrell RE, Goodpaster BH, Kelley DE (2005) Effects of weight loss and physical activity on skeletal muscle mitochondrial function in obesity. Am J Physiol Endocrinol Metab 288:E818-E825. doi:10.1152/ajpendo.00 322.2004

Menshikova EV, Ritov VB, Ferrell RE, Azuma K, Goodpaster BH, Kelley DE (2007) Characteristics of skeletal muscle mitochondrial biogenesis induced by moderate-intensity exercise and weight loss in obesity. J Appl Physiol 103:21-27. doi:10.1152/ japplphysiol.01228.2006

Miller FJ, Rosenfeldt FL, Zhang C, Linnane AW, Nagley P (2003) Precise determination of mitochondrial DNA copy number in human skeletal and cardiac muscle by a PCR-based assay: lack of change of copy number with age. Nucleic Acids Res 31:e61

Moseley L, Jeukendrup AE (2001) The reliability of cycling efficiency. Med Sci Sports Exerc 33:621-627

Ono T, Isobe K, Nakada K, Hayashi JI (2001) Human cells are protected from mitochondrial dysfunction by complementation of DNA products in fused mitochondria. Nat Genet 28:272-275. doi: $10.1038 / 90116$

Phillips SM, Green HJ, Tarnopolsky MA, Heigenhauser GJ, Grant SM (1996) Progressive effect of endurance training on metabolic adaptations in working skeletal muscle. Am J Physiol 270:E265E272

Pilegaard H, Saltin B, Neufer PD (2003) Exercise induces transient transcriptional activation of the PGC-1alpha gene in human skeletal muscle. J Physiol 546:851-858 PHY_034850[pii]
Schmutz S, Dapp C, Wittwer M, Vogt M, Hoppeler H, Fluck M (2006) Endurance training modulates the muscular transcriptome response to acute exercise. Pflugers Arch 451:678-687. doi: 10.1007/s00424-005-1497-0

Schrauwen P, Hesselink MK, Vaartjes I et al (2002) Effect of acute exercise on uncoupling protein 3 is a fat metabolism-mediated effect. Am J Physiol Endocrinol Metab 282:E11-E17

Schrauwen P, Russell AP, Moonen-Kornips E, Boon N, Hesselink MK (2005) Effect of 2 weeks of endurance training on uncoupling protein 3 content in untrained human subjects. Acta Physiol Scand 183:273-280. doi:10.1111/j.1365-201X.2004. 01393.x

Siri WE (1993) Body composition from fluid spaces and density: analysis of methods. 1961. Nutrition 9:480-491 discussion 480, 492

Szuhai K, Ouweland J, Dirks R et al (2001) Simultaneous A8344G heteroplasmy and mitochondrial DNA copy number quantification in myoclonus epilepsy and ragged-red fibers (MERRF) syndrome by a multiplex molecular beacon based real-time fluorescence PCR. Nucleic Acids Res 29:E13

Tunstall RJ, Mehan KA, Wadley GD et al (2002) Exercise training increases lipid metabolism gene expression in human skeletal muscle. Am J Physiol Endocrinol Metab 283:E66-E72. doi: 10.1152/ajpendo.00475.2001

Wang S, Subramaniam A, Cawthorne MA, Clapham JC (2003) Increased fatty acid oxidation in transgenic mice overexpressing UCP3 in skeletal muscle. Diabetes Obes Metab 5:295-301 273[pii]

Wende AR, Schaeffer PJ, Parker GJ et al (2007) A role for the transcriptional coactivator PGC-1alpha in muscle refueling. J Biol Chem 282:36642-36651. doi:10.1074/jbc.M707006200

Wojtaszewski JF, MacDonald C, Nielsen JN et al (2003) Regulation of $5^{\prime}$ AMP-activated protein kinase activity and substrate utilization in exercising human skeletal muscle. Am J Physiol Endocrinol Metab 284:E813-E822. doi:10.1152/ajpendo.00436. 2002

Yeo WK, Paton CD, Garnham AP, Burke LM, Carey AL, Hawley JA (2008) Skeletal muscle adaptation and performance responses to once a day versus twice every second day endurance training regimens. J Appl Physiol 105:1462-1470. doi:10.1152/jappl physiol.90882.2008 